OPEN ACCESS

Edited by:

Ivo lavicoli,

University of Naples Federico II,

Italy

Reviewed by:

Gabriele Giorgi,

European University of Rome, Italy

Veruscka Leso,

Catholic University of the Sacred

Heart of Rome, Italy

${ }^{*}$ Correspondence:

Silja Bellingrath

silja.bellingrath@uni-due.de

Specialty section:

This article was submitted to Occupational Health and Safety,

a section of the journal

Frontiers in Public Health

Received: 18 January 2017

Accepted: 28 July 2017

Published: 17 August 2017

Citation:

Metzler YA and Bellingrath S (2017)

Psychosocial Hazard Analysis in

a Heterogeneous Workforce:

Determinants of Work Stress in

Blue- and White-Collar Workers

of the European Steel Industry.

Front. Public Health 5:210.

doi: 10.3389/fpubh.2017.00210

\section{Psychosocial Hazard Analysis in a Heterogeneous Workforce: Determinants of Work Stress in Blue- and White-Collar Workers of the European Steel Industry}

\author{
Yannick Arnold Metzler and Silja Bellingrath* \\ Work and Organizational Psychology, University of Duisburg-Essen, Essen, Germany
}

The European steel industry's workforce is highly heterogeneous and consists of various occupational groups, presumably facing different psychosocial stressors. The few existing studies on the subject mainly focused on physical constraints of blue-collar workers, whereas the supposable psychosocial workload received only little research attention. This is remarkable considering the challenges associated with statutory required risk assessment of psychosocial hazards. Valid measures of hazard analysis must account for various stressors and reliably identify them, also between occupational groups. The present study, based on a sample of blue- and white-collar workers $(N=124)$ from the European steel industry, aims to provide a first insight into psychosocial stressors and strain at work in this rarely researched industrial sector. Furthermore, two well-known theoretical roadmaps in job analysis are examined regarding their utility for risk assessment in heterogeneous workforces: the German standard version of the Copenhagen Psychosocial Questionnaire (COPSOQ) and the short version of the effort-reward imbalance questionnaire. Hierarchical multiple regression analyses revealed that the COPSOQ was better suited to predict various strain indices in the present sample. Especially stressors relating to socioemotional aspects, such as work-privacy conflict, revealed a reasonable impact, indicating the need for comprehensive solutions at the organizational level instead of solutions focusing on single workplaces. To conclude, a broadly diversified and validated approach in psychosocial risk assessment is needed to adequately assess the variety of psychosocial factors at work and in different occupational groups.

Keywords: workload, Copenhagen Psychosocial Questionnaire, effort-reward imbalance, occupational stress, steel industry

\section{INTRODUCTION}

Sector-specific characteristics of psychosocial stressors and strain in the European steel industry have rarely been investigated so far. Considering the fact that this branch is one of the key industries in Europe, as well as in Germany, this is surprising. Existing sources describe several potential work specific stressors mainly caused by heavy work, organizational factors, and economic conditions (1). Based on the fifth European Working Conditions Survey, the European Foundation for the 
Improvement of Living and Working Conditions (2) concludes that employees working in the metal industry are generally exposed to high physical risks, atypical working hours in terms of shift work, high demands, and low autonomy. In line with these findings, the occupational medical French SUMER survey of the DARES (French Ministry of Labour) emphasizes for example constraints in posture and articular stress, noise pollution, and manual handling of loads as main physical demands (3). The Stress Report of the German Federal Institute of Occupational Safety and Health (BAuA) notes that employees within the metal industry report reoccurring work processes, predefined standards in quantity, performance and time, low influence and a detailed prescription of workmanship. In addition, a good cooperation with colleagues and being part of a community are mentioned as resources (4). These conditions already illustrate a variety of presumable sources possibly evoking psychosocial stress, especially when keeping in mind that job demands, control and social interactions are known to be potent predictors of adverse work-related outcomes (5-9).

Besides the above mentioned aspects, restructuring and downsizing of the steel industry due to a challenging globalized market lead to consequences like job losses, perceived job insecurity and various changes in work activities and organizations $(1,10)$, resulting in increasing levels of psychosocial stress (11). Even though the steel industry is primarily a male blue-collar working sector (10), the need for indispensable business operating areas such as sales and distribution, research and development or financial administration result in a heterogeneous workforce (1), including also white-collar occupations that underlie equal sector-specific circumstances. Traditionally, there has been a greater interest in adverse outcomes caused by environmental and physical factors, and thus a major focus on examining blue-collar steel workers. Besides general sources describing such types of occupational hazards as published from the International Iron and Steel Institute and the United Nations Environment Programme (12) as well as the International Labor Organization (13), there has been a number of studies investigating the impact of heavy work on for instance low back pain in different steel working occupations (14-16). Furthermore, a large number of studies on exposure to chemical and other physical hazards across different industries have been published, which are not further dealt with here. Less, however, is known about the characteristics and structure of possible psychosocial stressors in the European steel industry's work environment. Büssing (17) for example assessed the psychological consequences of job insecurity in the German steel industry. Further research emphasis has been placed on the analysis of shift work such as the impact of differing shift systems on sleep quality or cardiovascular risks $(18,19)$, or the significance of work experience in limiting fatigue and preventing accidents during night shifts (20). Whereas the studies summarized above addressed the relationship between a specific, predefined risk factor and various strain outcomes, the aim of the present study is a more general evaluation of potential stressor-strain associations in the German steel industry. It is not clear whether the steel industry's work environment and the resulting determinants of strain differ from or, respectively correspond to previous findings in other industrial sectors. This is important since regulations and procedures on psychosocial risk assessment formulated by institutions of the European Union, e.g., the framework directive $89 / 391 / \mathrm{EEC}$ (21) and the guidance on risk assessment at work (22), demand employers to measure, evaluate, and deal with psychosocial hazards at work. To conclude, we hypothesize the steel industry's workforce to be a rather heterogeneous and highly risk-exposed occupational group that may face various presumable sources of psychosocial stress. Hence, we consider that a universal, wide-ranged measurement approach is needed to adequately examine and compare both psychosocial workload and strain in this setting.

Several instruments assessing psychosocial factors at work have been developed in the past years $(23,24)$, usually aiming to quantify perceived workload by employees on a Likert scalebased rating procedure. Besides known and validated instruments of stress and job analysis developed in Germany like the Trier Inventory for Chronic Stress (25), the salutogenic subjective work analysis (SALSA) (26), or the instrument for stress-oriented job analysis (ISTA) (27), a remarkable number of instruments for psychosocial hazard analysis in Germany consists of short forms, checklists, and/or non-validated questionnaires. Such approaches seem questionable, since neither sound evidence nor the diverse facets of workplace characteristics become visible. Validated and comprehensive measurement approaches should be preferred in this respect. Scientific literature and practice often refer to the effort-reward imbalance (ERI) model (6) as a theoretical roadmap for describing the emergence and characteristics of psychosocial stress. During the last decade it has proven its predictive ability in a large number of prospective epidemiological cohort studies, including different working populations as well as in experimental setups, especially with regard to cardiovascular diseases and affective disorders, but also with regard to further negative health outcomes (28-31). The ERI model postulates psychosocial work stress to be a result of failed social reciprocity, thereby emphasizing social factors in the etiology of health and disease. Siegrist (6) hypothesizes a recurrent disappointment in the basic principle of reciprocity at work, namely an imbalance between high efforts spent and low rewards received, to affect health and well-being by compromising crucial self-regulatory functions and eliciting negative emotions and associated psychobiological stress responses $(6,32)$. The ERI model furthermore states that failed social reciprocity is often experienced by individuals with little or no alternative choices in the labor market, those exposed to a strong job competition and those characterized by higher levels of overcommitment. This intrinsic component, a motivational pattern of excessive work-related commitment is assumed to strengthen the perception of failed social reciprocity but was also shown to independently affect health outcomes (33-35). With respect to the stress-theoretical basis of the model, the experience of ERI is assumed to result in a sustained activation of the stress axes and to trigger distinct areas in the brain's reward circuitry, thereby suppressing the production of dopamine and oxytocin, neurotransmitters with stress-buffering properties. In the setting of industrial occupations, Schmidt et al. (36) for instance examined the role of ERI as a predictor of the metabolic syndrome in a German cohort study of industrial employees $(N=4.141)$. 
The analysis showed that employees belonging to the high ERI group had a $29 \%$ higher chance for developing a metabolic syndrome compared to the low ERI group. A further study based on data of an occupational cohort $(N=2.674)$ by Li et al. (37) revealed high ERI to be related to diabetes and prediabetes with a $27 \%$ chance greater compared to low ERI in men.

Another approach to assess the determinants of psychosocial stress at work, which is not based on one specific theoretical construct, is the Copenhagen Psychosocial Questionnaire (COPSOQ) (38) of the Danish National Institute for Occupational Health. Aiming to assess psychosocial workload on a broader level, several of the established theories concerning psychosocial stress at work were combined: (1) the job characteristics model, (2) the Michigan organizational stress model, (3) the demandcontrol-(support) model, (4) the socio-technical approach, (5) the action-theoretical approach, (6) the ERI model, and (7) the vitamin model $(39,40)$. The elucidation of these models is beyond the scope of this article. The COPSOQ does not substantially consist of newly developed items; instead, its scales are mainly composed of already existing and validated instruments, like, for instance, the Setterlind Stress Profile (41) or the ShortForm 36 health survey (42). Thus, the COPSOQ represents a multifactorial approach to assess a variety of constructs in order to establish a combined risk profile. The aim to achieve high construct validity regarding psychosocial factors at work in general (43) makes it a valuable instrument especially for operational practices (44) such as psychosocial risk assessment. The COPSOQ, furthermore, includes items assessing stressors such as quantitative demands, influence at work or quality of leadership as well as strain indices such as job satisfaction, or self-reported general health. The COPSOQ scales have been widely used in Danish and international studies (43, 45-47). A prospective study examining psychosocial workload in terms of the COPSOQ as a risk factor for long-term sickness absence among 5.141 Danish employees (46), for example, concluded that emotional demands and demands for hiding emotions significantly predicted long-term sickness absence among men. Another prospective study from Denmark $(N=4.133)$ measured the impact of psychosocial work characteristics on the incidence of severe depressive symptoms (47). The analysis revealed an increased risk for women with low influence at work and low support from supervisors, whereas, men were at severe risk when they considered their jobs to be precarious. Recent reviews furthermore report associations of psychosocial factors at work with musculoskeletal disorders (48-50), mental health problems, mostly depressive symptoms and anxiety $(7,51,52)$, and organizational outcomes such as job satisfaction $(53,54)$ or accidents and injuries, as was recently demonstrated in a sample of Iranian steel workers (55). Cooper et al. (56) suggest workplace stress to be responsible for $60-80 \%$ of all work-related accidents.

\section{Study Objectives}

The present data were collected as part of a pilot study to examine psychosocial hazards in terms of occupational risk assessment in a German company of the steel industry. The objectives of this study were (1) to provide insight into the possibly wide-ranged scope of psychosocial work stressors and strain in the European steel industry and (2) to attain information about the utility of the COPOSQ and the ERI-questionnaire for psychosocial risk assessment, especially in view of the steel industry's heterogenous workforce. (2.1) The variance explained by belonging to different working groups (blue collar and white collar) was examined, as a sufficient discriminatory power can be informative for determining plausible differences and information about relevant psychosocial factors between occupational groups. This knowledge is crucial since measures of hazard analysis must provide Occupational Health and Safety (OHS) with clear information about workplace characteristics. (2.2) We, then, tested both the COPSOQ- and the ERI-questionnaire in view of their own as well as their combined power in predicting work-related outcomes measured by the COPSOQ.

\section{MATERIALS AND METHODS}

\section{Study Sample}

The current study is based on cross-sectional data from a sample of 124 employees working in the same German steel-manufacturing company. The sample includes two working areas, an administrative $(N=74$, white-collar occupation) and a production area ( $N=50$, blue-collar occupation). Next to sociodemographic characteristics (gender and age in groups), hierarchical position, working volume, length of company affiliation, length of working experience, and type of working contract were measured as additional confounders. The white-collar group mainly consisted of sales representatives in strategy and planning, while the blue-collar group comprised tasks, such as welding, scaffold construction, and metal maintenance works, organized in fully continuous shift systems.

\section{Procedure}

The study took place in March 2016 and was approved by the occupational review boards for data protection and work safety. A working councils' agreement including the data protection officer's agreement ensuring compliance with all relevant privacy policy regulations according to German law was adopted. A member of the working council was present during the data collection process to ensure compliance with the agreement and to guarantee anonymity and voluntary participation. Completed questionnaires had to be put into a sealed ballot box by the employees. To increase acceptance and response rate, the required time to complete the questionnaires was granted as working time. Furthermore, the employees were surveyed directly at the workplace, were supplied with information material before and could ask questions during the survey. A full response rate was acquired.

\section{Measures}

\section{Effort-Reward-Imbalance Questionnaire}

To assess ERI, we used its validated German short form, consisting of the three 4-point Likert-scaled dimensions effort (3 items), reward ( 7 items), and overcommitment (6 items). All scales are calculated as sum scores. Effort scores range from 3 to 12, reward from 7 to 28 , and overcommitment from 6 to 24, pointing two 
low or high efforts spent, rewards received and overcommitment, respectively. The imbalance between effort and reward is constructed as a ratio with the effort score in the nominator and the reward score in the denominator. To adjust the unequal number of items, the ratio is multiplied with a correction factor calculated as the ratio of reward and effort items (57).

\section{Copenhagen Psychosocial Questionnaire}

The standard version of the German COPSOQ (44) examines psychosocial workload and strain by the four main scales: demands (14 items, subscales quantitative demands, emotional demands, demands for hiding emotions, work-privacy conflict), influence and development (19 items, subscales influence at work, degree of freedom, possibilities for development, meaning of work, workplace commitment), interpersonal relations and leadership (26 items, subscales predictability, role-clarity, roleconflicts, quality of leadership, social support, feedback, social relations, sense of community, mobbing), outcomes (24 items, subscales intention to leave the job, job satisfaction, general health, personal burnout, cognitive stress symptoms, satisfaction with life), and one further scale on insecurity at work (4 items). These dimensions consist of 25 subscales, which we extended by the subscale trust and justice ( 4 items, interpersonal relations and leadership) with reference to the Freiburg research centre for occupational sciences (FFAW) (58). Item responses score on Likert scales of 4, 5, and 7 points on a $0-100$ range. All scales are calculated as average scores. In order to facilitate the interpretation of our results, the coding of the COPSOQ scales was slightly modified in the present study. Higher average scores now universally indicate higher psychosocial stressors and strain.

\section{Statistical Analysis}

Concerning the COPSOQ, less than $1 \%$ of all values contained missing data. Little's MCAR test $(p=0.525)$ and graphical analysis showed no evidence for a systematic bias. We, therefore, imputed missing values of the COPSOQ by the mean score of the respective subscale, if at least half of its items were rated. Otherwise, the rating was declared as missing. In view of the ERI, we considered list-wise deletion to be more appropriate because most of its missing data occurred from only three almost unanswered questionnaires. In general, the application of advanced techniques, such as multiple imputation, would have been a disproportional effort to generate just a small amount of data. In a first step, we compared the levels of stress and strain assessed with the COPSOQ with available reference data on a descriptive level (59). Afterward, Cronbach's alpha was assessed to provide reliability measures. To determine how belonging to the blue- or white-collar working group may affect the ratings, we calculated partial eta ${ }^{2}$ as effect size measure for all subscales using analysis of variance (ANOVA). Partial eta ${ }^{2}$ reflects the extent to which proportions of variance are attributable to a categorical variable and is similar to $R^{2}$ in multiple linear regression (60). As our sample is non-representative, we compared our results with those of the German COPSOQ validation study. Cohen (61) suggests explained variances from $1 \%$ to indicate a small, from $6 \%$ a medium and from $14 \%$ a large effect. We, therefore, only present explained variances of partial eta ${ }^{2} \geq 0.01$. To assess the ability of the ERI and the COPSOQ to predict the strain outcomes inherent in the COPSOQ, we conducted hierarchical multiple regression analyses for each questionnaire. We also tested whether the predictive power would increase by combining both models.

\section{RESULTS}

\section{Sample Characteristics}

Table 1 shows the sample characteristics and distributions of the following covariates: number of participants, age in groups, gender, hierarchical position, working volume, average length of company affiliation in years, average length of working experience in years (current activity) and type of working contract, each per working group and in total. Obtainable information showed that 88 (71\%) participants were male and $32(28.5 \%)$ female. Age was categorized in eight groups for reasons of data protection. The median of 4.5 indicates most participants to be of middle to older age. The total average length of company affiliation was 22 years and the total average length of working experience 14 years. The table reveals clear differences of the socio-demographic characteristics between the two groups. The blue-collar group for instance solely consists of older male workers whereas the white-collar group almost equally comprises younger to middle-aged men and women. This, however, depicts the industry's prevailing structure as has been mentioned in the Section "Introduction."

Figure 1 presents the average scores of the COPSOQ scales within both working groups, compared to the reference values available from the German COPSOQ-databank $(N=10.022)$ (59). This databank does not encompass a population-based representative sample; however, it provides a job-exposure matrix mostly reflecting the actual distribution of occupations in Germany. In the context of hazard evaluation, scorings higher than the reference value indicate a need for action. In Germany, classifying psychosocial hazards as risks requires either (1) using standardized instructions provided by the research tool, (2) comparing own data with available reference values for detecting discrepancies, (3) elaborating and evaluating hazards via group

TABLE 1 | Sample characteristics.

\begin{tabular}{lccc}
\hline Working group & $\begin{array}{c}\text { Blue } \\
\text { collar }\end{array}$ & $\begin{array}{c}\text { White } \\
\text { collar }\end{array}$ & Total \\
\hline$N$ & 50 & 74 & 124 \\
Median grouped age & 6 & 4 & 4.5 \\
Gender M/W & $49 / 0$ & $39 / 32$ & $88 / 32$ \\
Position (employee/specialist/supervisor) & $41 / 8 / 1$ & $55 / 1 / 15$ & $96 / 9 / 16$ \\
Working volume (full time/>50\% time/<50\% & $50 / 0 / 0$ & $67 / 4 / 3$ & $117 / 4 / 3$ \\
time) & & & \\
Average length of company affiliation in years & 27 & 19 & 22 \\
Average length of working experience in years & 17 & 12 & 14 \\
Type of working contract (fixed-term yes/no) & $6 / 43$ & $7 / 67$ & $13 / 110$ \\
\hline
\end{tabular}

$M$, men, $W$, women.

Age groups from 1 to 8: (1) up to 25 years, (2) 26-30 years, (3) 31-35 years, (4) 36-40 years, (5) 41-45 years, (6) 46-50 years, (7) 51-55 years, (8) over 55 years. 


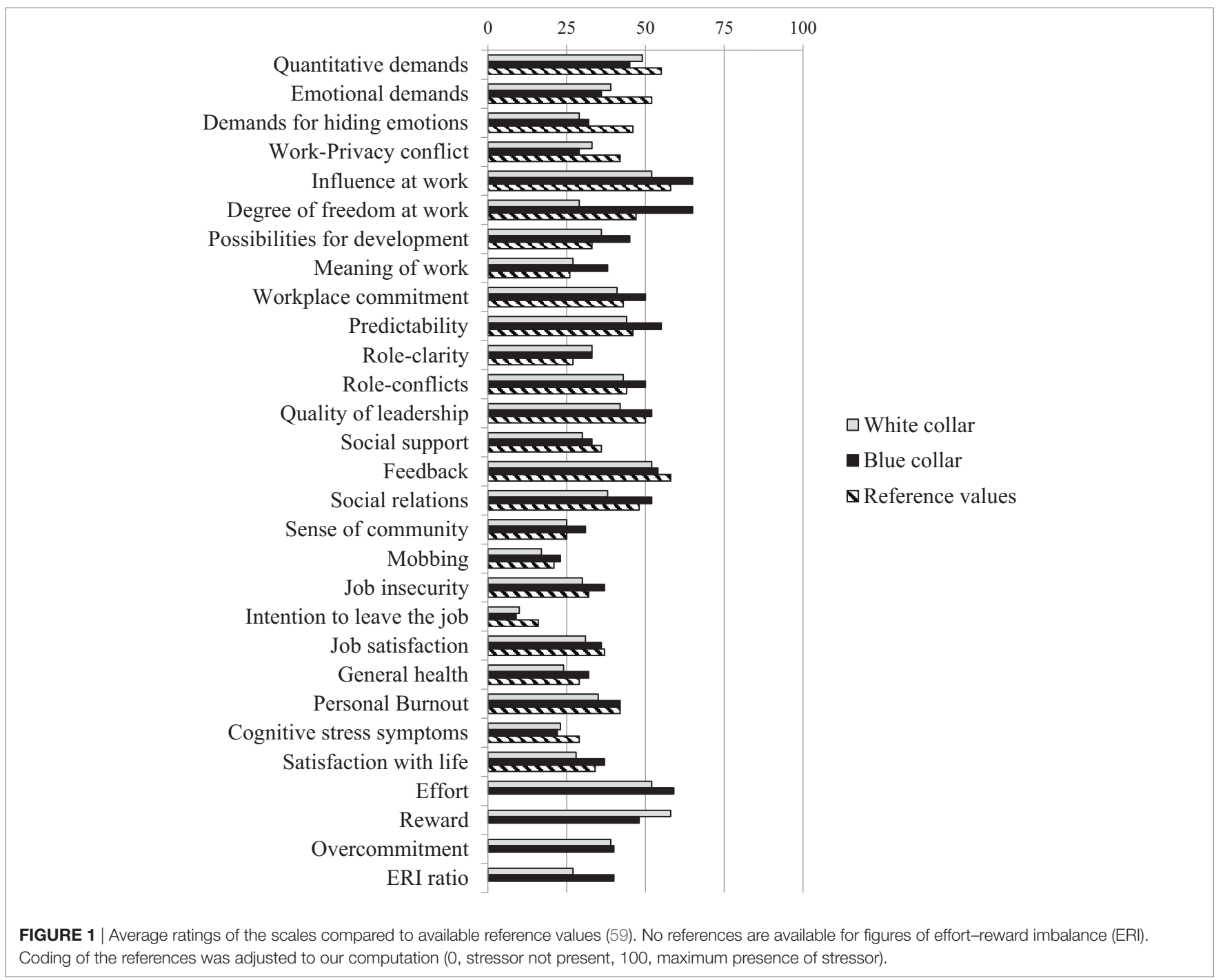

discussions, or (4) conducting strain analyses (62). Examining the figures reveals that especially the ratings of the blue-collar group mostly exceed the reference values. Scores are especially high on scales like predictability (lack of information), roleconflicts, social relations, and the entire influence dimension and exceed both the reference values and the average ratings of the white-collar group. The white-collar group only shows slight deviations from the reference values in the scales possibilities for development and meaning of work and a stronger one in roleclarity. To facilitate the comparability, we transposed the ERI scales and the ERI-ratio to a 0-100 range in accordance to the COPSOQ scales (see Figure 1). In this case, no global reference values were available. Yet, Nübling et al. (43) provide comparative figures for several different occupations.

\section{Reliability of the Scales and Variance Explained by Working Group}

All in all, the scales show satisfying reliability scores in terms of Cronbach's alpha (see Table 2). Especially when keeping in mind that most scales used in the study are comprised of only 4-8 items and a higher number of items is likely to result in higher Cronbach's alpha values (63). Merely, the scales feedback $(\alpha=0.49)$ and social relations $(\alpha=0.27)$ revealed low reliability scores (both 2 -item scales) and were, therefore, not included in the analyses.

As described above, effect size measures were then computed to examine the power of both instruments in distinguishing different types of psychosocial stressors and strain (see Table 3). As expected, partial eta ${ }^{2}$ estimates differed between the present study and the German COPSOQ validation study, although some similar patterns became apparent. The scale degree of freedom at work showed the highest amounts of variance explained by working group in both our $\left(\eta_{p}^{2}=0.53\right)$ and the validation study $\left(\eta_{p}^{2}=0.47\right)$. With respect to the scales degree of freedom at work [M(blue collar $)=65, \mathrm{M}($ white collar $)=29]$ and influence at work $[\mathrm{M}($ blue collar $)=65, \mathrm{M}$ (white collar $)=52]$, the effect size measures indicated lower (perceived) degrees of freedom and influence at work within the industrial occupations group. Similar conclusions can be drawn with respect to the other scales. In view of the ERI, 
TABLE 2 | Cronbach's alpha of the scales.

\begin{tabular}{|c|c|c|}
\hline Scales & Number of items & Cronbach's $\alpha$ \\
\hline \multicolumn{3}{|l|}{ Copenhagen Psychosocial } \\
\hline \multicolumn{3}{|l|}{ Questionnaire } \\
\hline Quantitative demands & 4 & 0.75 \\
\hline Emotional demands & 3 & 0.80 \\
\hline Demands for hiding emotions & 2 & 0.81 \\
\hline Work-privacy conflict & 5 & 0.92 \\
\hline Influence at work & 4 & 0.79 \\
\hline Degree of freedom at work & 4 & 0.81 \\
\hline Possibilities for development & 4 & 0.84 \\
\hline Meaning of work & 3 & 0.86 \\
\hline Workplace commitment & 4 & 0.77 \\
\hline Predictability & 2 & 0.67 \\
\hline Role-clarity & 4 & 0.76 \\
\hline Role-conflicts & 4 & 0.73 \\
\hline Quality of leadership & 4 & 0.93 \\
\hline Social support & 4 & 0.72 \\
\hline Sense of community & 3 & 0.83 \\
\hline Mobbing & 1 & - \\
\hline Trust and justice & 4 & 0.82 \\
\hline Job insecurity & 4 & 0.65 \\
\hline Intention to leave the job & 1 & - \\
\hline Job satisfaction & 7 & 0.82 \\
\hline General health & 1 & - \\
\hline Personal Burnout & 6 & 0.86 \\
\hline Cognitive stress symptoms & 4 & 0.84 \\
\hline Satisfaction with life & 5 & 0.89 \\
\hline \multicolumn{3}{|c|}{ Effort-Reward Imbalance (ERI) } \\
\hline Effort & 3 & 0.63 \\
\hline Reward & 7 & 0.75 \\
\hline Overcommitment & 6 & 0.79 \\
\hline Effort-reward (ERI) ratio & Interaction term & - \\
\hline
\end{tabular}

the reward scale and the ERI-ratio revealed significant medium effects corresponding to the descriptive results.

\section{Regression Models}

In a next step, we examined which stressors and psychosocial workplace characteristics in terms of the COPSOQ and ERI scales predict self-reported strain assessed with the COPSOQ. Considering the substantial number of potential predictors, hierarchical multiple regression analyses were carried out to achieve a better accuracy. Tables 4-9 present first the COPSOQ's regression analyses for each outcome. While model 1 always presents the covariates only, predictors were then included in stages if they improved the model by explaining at least an additional increase of two percent of variance $\left(R^{2}\right)$. If not, they were excluded. We accepted these minor changes in $R^{2}$ to be relevant. When keeping the multifactorial stress-strain relation in mind it is likely that desirable associations are already found at low to moderate levels $(44,64)$. Thus, the following models show the accepted predictors and their standardized beta weight, as well as $R^{2}$, adjusted $R^{2}$ and change in $R^{2}$.

Job satisfaction was the outcome with the highest amount of variance explained. The most frequently observed significant predictor was work-privacy conflict, associated with general health, personal burnout, and cognitive stress symptoms. Furthermore, especially scales like meaning of work, social support and work-privacy conflict predicted several of the strain
TABLE 3 | Analysis of variance to assess explained variance by working group (blue collar versus white collar) compared to the German validation study.

\begin{tabular}{|c|c|c|c|}
\hline \multirow[t]{2}{*}{ Scales } & \multicolumn{2}{|c|}{ Current study } & \multirow{2}{*}{$\frac{\begin{array}{c}\text { Validation } \\
\text { study }\end{array}}{\eta_{p}^{2}}$} \\
\hline & $F$ & $\eta_{p}^{2}$ & \\
\hline \multicolumn{4}{|l|}{ Copenhagen Psychosocial } \\
\hline \multicolumn{4}{|l|}{ Questionnaire } \\
\hline Quantitative demands & $1.875(1,117)$ & 0.02 & $0.12^{\star \star}$ \\
\hline Emotional demands & $0.521(1,117)$ & 0.00 & $0.25^{\star \star}$ \\
\hline Demands for hiding emotions & $0.637(1,119)$ & 0.01 & $0.03^{\star \star}$ \\
\hline Work-privacy conflict & $0.558(1,120)$ & 0.01 & $0.16^{\star \star}$ \\
\hline Influence at work & $15.237(1,118)$ & $0.11^{\star \star}$ & $0.07^{\star \star}$ \\
\hline Degree of freedom at work & $132.972(1,117)$ & $0.53^{\star \star}$ & $0.47^{\star \star}$ \\
\hline Possibilities for development & $6.937(1,121)$ & $0.05^{\star}$ & $0.13^{\star \star}$ \\
\hline Meaning of work & $9.796(1,121)$ & $0.08^{\star \star}$ & $0.12^{\star \star}$ \\
\hline Workplace commitment & $5.645(1,121)$ & $0.05^{\star}$ & $0.07^{\star \star}$ \\
\hline Predictability & $9.703(1,121)$ & $0.07^{\star \star}$ & $0.05^{\text {** }}$ \\
\hline Role-clarity & $0.015(1,119)$ & 0.00 & $0.05^{\star \star}$ \\
\hline Role-conflicts & $4.178(1,120)$ & $0.03^{*}$ & $0.04^{* \star}$ \\
\hline Quality of leadership & $4.504(1,120)$ & $0.04^{*}$ & $0.04^{\star \star}$ \\
\hline Social support & $0.844(1,121)$ & 0.01 & $0.06^{\star \star}$ \\
\hline Sense of community & $3.956(1,122)$ & $0.03^{*}$ & $0.02^{\star \star}$ \\
\hline Mobbing & $2.485(1,121)$ & 0.02 & $0.03^{\text {** }}$ \\
\hline Trust and justice & $2.999(1,118)$ & 0.03 & - \\
\hline Job insecurity & $3.307(1,122)$ & 0.03 & $0.10^{* *}$ \\
\hline Intention to leave the job & $0.263(1,120)$ & 0.00 & $0.02^{\star *}$ \\
\hline Job satisfaction & $4.841(1,118)$ & $0.04^{*}$ & $0.02^{\star \star}$ \\
\hline General health & $5.723(1,121)$ & $0.05^{\star}$ & $0.05^{\star \star}$ \\
\hline Personal Burnout & $7.452(1,122)$ & $0.06^{\star \star}$ & $0.11^{\star \star}$ \\
\hline Cognitive stress symptoms & $0.791(1,122)$ & 0.00 & $0.02^{* \star}$ \\
\hline Satisfaction with life & $8.615(1,121)$ & $0.07^{\star \star}$ & $0.02^{* *}$ \\
\hline \multicolumn{4}{|c|}{ Effort-Reward Imbalance (ERI) } \\
\hline Effort & $3.742(1,115)$ & 0.03 & - \\
\hline Reward & $10.929(1,1,009)$ & $0.09^{\star *}$ & - \\
\hline Overcommitment & $0.107(1,114)$ & 0.00 & - \\
\hline ERI-ratio & $13.474(1,107)$ & $0.11^{\star \star}$ & - \\
\hline
\end{tabular}

Validation study [N=2,561, Nübling et al. (44)] did not include ERI.

${ }^{*} p<0.05$.

${ }^{* *} p<0.01$

indices. Almost all subscales conformed to theory considering the (linear) relationship between stress and strain. Merely, the negative relationship between quantitative demands and general health is arguable, as it does not fit to common theory at first glance. Since both working groups scored rather low on this scale $[\mathrm{M}($ blue collar $)=32, \mathrm{M}($ white collar $)=24]$, it is conceivable that an exposure at this level is perceived positively. A greater range of scorings in quantitative demands might have resulted in different findings. Surprisingly, the scale job insecurity showed no significant contribution at all. The ERI-questionnaire offers the possibility to assess the outcomes on a subscale level or via the ratio. Regression models of the transposed subscales effort, reward, and overcommitment, are shown in Tables 10-13. Although an association between the scales and the strain indices can be determined, the predictive power was significantly lower compared to the COPSOQ-models. The outcomes intention to leave the job and general health had to be excluded because of violations to the model fit. Job satisfaction again showed the largest amount of variance explained and the scales overcommitment and reward were the most frequent predictors. Testing the ratio 
TABLE 4 | Hierarchical regression analysis of predictors of intention to leave the job (Copenhagen Psychosocial Questionnaire model).

\begin{tabular}{|c|c|c|c|}
\hline \multirow[t]{2}{*}{ Predictors } & \multirow{2}{*}{$\frac{\text { Model 1 }}{\beta}$} & \multirow{2}{*}{$\frac{\text { Model } 2}{\beta}$} & \multirow{2}{*}{$\frac{\text { Model } 3}{\beta}$} \\
\hline & & & \\
\hline Working area & -0.002 & -0.096 & -0.105 \\
\hline Gender & -0.094 & -0.149 & -0.159 \\
\hline Age & -0.215 & -0.273 & -0.324 \\
\hline Position & 0.109 & 0.170 & 0.196 \\
\hline Working volume & 0.271 & 0.196 & 0.145 \\
\hline Company affiliation & 0.010 & 0.032 & 0.059 \\
\hline Working experience & -0.060 & -0.031 & -0.040 \\
\hline Type of working contract & $-0.253^{*}$ & -0.196 & -0.115 \\
\hline Meaning of work & & $0.337^{\star \star}$ & $0.293^{\star \star}$ \\
\hline Social support & & & $0.248^{\star}$ \\
\hline$R^{2}$ & 0.094 & $0.188^{\star}$ & $0.238^{\star \star}$ \\
\hline adj. $R^{2}$ & 0.015 & $0.107^{\star}$ & $0.153^{\star \star}$ \\
\hline$\Delta R^{2}$ & 0.094 & $0.094^{\star \star}$ & $0.050^{\star}$ \\
\hline
\end{tabular}

Predictors were included if they explained at least additional $2 \%$ of variance.

${ }^{*} p<0.05$.

${ }^{* *} p<0.01$.

${ }^{* * *} p<0.001$

TABLE 5 | Hierarchical regression analysis of predictors of job satisfaction (Copenhagen Psychosocial Questionnaire model).

\begin{tabular}{|c|c|c|c|c|c|}
\hline \multirow[t]{2}{*}{ Predictors } & \multirow{2}{*}{$\frac{\text { Model 1 }}{\beta}$} & \multirow{2}{*}{$\frac{\text { Model } 2}{\beta}$} & \multirow{2}{*}{$\frac{\text { Model } 3}{\beta}$} & \multirow{2}{*}{$\frac{\text { Model } 4}{\beta}$} & \multirow{2}{*}{$\frac{\text { Model } 5}{\beta}$} \\
\hline & & & & & \\
\hline Working area & $0.327^{\star \star}$ & -0.027 & -0.065 & -0.149 & -0.141 \\
\hline Gender & 0.140 & 0.153 & 0.059 & 0.126 & 0.116 \\
\hline Age & -0.159 & -0.289 & $-0.317^{\star}$ & $-0.378^{\star \star}$ & $-0.356^{\star \star}$ \\
\hline Position & $-0.263^{\star}$ & $-0.190^{\star}$ & -0.113 & -0.097 & -0.080 \\
\hline Working volume & 0.245 & 0.178 & 0.078 & 0.038 & 0.021 \\
\hline Company affiliation & 0.033 & 0.076 & 0.082 & 0.177 & 0.166 \\
\hline Working experience & 0.073 & -0.007 & 0.056 & 0.122 & 0.118 \\
\hline $\begin{array}{l}\text { Type of working } \\
\text { contract }\end{array}$ & -0.184 & -0.138 & -0.073 & -0.005 & 0.015 \\
\hline $\begin{array}{l}\text { Degree of freedom } \\
\text { at work }\end{array}$ & & $0.540^{\star \star \star}$ & $0.348^{\star \star}$ & $0.357^{\star \star \star}$ & $0.339^{\star \star \star}$ \\
\hline Meaning of work & & & $0.550^{\star \star \star}$ & $0.398^{\star \star \star}$ & $0.350^{\star \star \star}$ \\
\hline Predictability & & & & $0.350^{\star \star \star}$ & $0.221^{\star *}$ \\
\hline Quality of leadership & & & & & $0.257^{\star \star}$ \\
\hline$R^{2}$ & $0.275^{\star \star}$ & $0.396^{\star \star}$ & $0.627^{\star \star}$ & $0.700^{\star \star}$ & $0.737^{\star \star}$ \\
\hline adj. $R^{2}$ & $0.207^{\star \star}$ & $0.332^{\star \star}$ & $0.582^{\star \star}$ & $0.659^{\star \star}$ & $0.698^{\star \star}$ \\
\hline$\Delta R^{2}$ & $0.275^{\star \star}$ & $0.121^{\star \star}$ & $0.231^{\star \star}$ & $0.072^{\star \star}$ & $0.037^{\star \star}$ \\
\hline
\end{tabular}

Predictors were included if they explained at least additional $2 \%$ of variance.

${ }^{*} p<0.05$.

${ }^{* *} p<0.01$.

${ }^{* * *} p<0.001$.

(results not shown) revealed a further substantial loss in predictive power, as the ratio merely explained $9 \%$ of variance in job satisfaction $\left(R^{2}=0.088, p<0.001\right)$ above the covariates. We also assessed whether combining both instruments would increase the predictive power. As this approach was not accompanied by significant improvements, we decided not to present these results.

\section{DISCUSSION}

In the current study, stressor-strain relationships were assessed in a sample of 124 blue- and white-collar employees of a German steel-manufacturing company, using the German standard version
TABLE 6 | Hierarchical regression analysis of predictors of general health (Copenhagen Psychosocial Questionnaire model).

\begin{tabular}{|c|c|c|c|}
\hline \multirow[t]{2}{*}{ Predictors } & \multirow{2}{*}{$\frac{\text { Model 1 }}{\beta}$} & \multirow{2}{*}{$\frac{\text { Model } 2}{\beta}$} & \multirow{2}{*}{$\frac{\text { Model } 3}{\boldsymbol{\beta}}$} \\
\hline & & & \\
\hline Working area & 0.100 & 0.097 & 0.125 \\
\hline Gender & 0.178 & 0.178 & 0.151 \\
\hline Age & $0.406^{\star}$ & $0.412^{\star}$ & $0.408^{\star}$ \\
\hline Position & -0.200 & -0.158 & -0.115 \\
\hline Working volume & -0.058 & -0.051 & -0.014 \\
\hline Company affiliation & -0.215 & -0.241 & -0.238 \\
\hline Working experience & 0.188 & 0.209 & 0.141 \\
\hline Type of working contract & 0.182 & 0.154 & 0.075 \\
\hline Quantitative demands & & -0.106 & $-0.294^{*}$ \\
\hline Work-privacy conflict & & & $0.332^{\star \star}$ \\
\hline$R^{2}$ & $0.189^{\star}$ & $0.198^{\star}$ & $0.271^{\star *}$ \\
\hline adj. $R^{2}$ & $0.117^{\star}$ & $0.116^{\star}$ & $0.187^{\star \star}$ \\
\hline$\Delta R^{2}$ & $0.189^{\star}$ & 0.021 & $0.052^{\star \star}$ \\
\hline
\end{tabular}

Predictors were included if they explained at least additional $2 \%$ of variance.

${ }^{*} p<0.05$.

${ }^{* *} p<0.01$.

${ }^{* * *} p<0.001$

TABLE 7 | Hierarchical regression analysis of predictors of personal burnout (Copenhagen Psychosocial Questionnaire model).

\begin{tabular}{|c|c|c|c|c|}
\hline \multirow[t]{2}{*}{ Predictors } & Model 1 & Model 2 & Model 3 & Model 4 \\
\hline & $\boldsymbol{\beta}$ & $\boldsymbol{\beta}$ & $\boldsymbol{\beta}$ & $\boldsymbol{\beta}$ \\
\hline Working area & $0.324^{\star \star}$ & $0.349^{\star \star}$ & $0.368^{\star \star \star}$ & $0.288^{\star \star}$ \\
\hline Gender & 0.228 & 0.156 & 0.169 & 0.122 \\
\hline Age & -0.134 & -0.250 & -0.229 & $-0.315^{\star}$ \\
\hline Position & 0.060 & -0.002 & -0.002 & 0.041 \\
\hline Working volume & 0.028 & 0.080 & 0.079 & 0.027 \\
\hline Company affiliation & -0.078 & -0.042 & -0.007 & 0.084 \\
\hline Working experience & 0.077 & 0.014 & -0.037 & -0.055 \\
\hline Type of working contract & 0.076 & 0.096 & 0.061 & 0.149 \\
\hline Emotional demands & & $0.407^{\star \star \star}$ & $0.248^{\star \star}$ & $0.246^{\star}$ \\
\hline Work-privacy conflict & & & $0.302^{\star \star}$ & $0.263^{\star \star}$ \\
\hline Sense of community & & & & $0.312^{\star \star}$ \\
\hline$R^{2}$ & $0.154^{\star}$ & $0.288^{* * *}$ & $0.352^{\star \star \star}$ & $0.433^{\star \star \star}$ \\
\hline adj. $R^{2}$ & $0.080^{\star}$ & $0.217^{* \star \star}$ & $0.279^{\star \star \star}$ & $0.363^{\star \star \star}$ \\
\hline$\Delta R^{2}$ & $0.154^{\star}$ & $0.134^{\star \star \star}$ & $0.064^{\star \star}$ & $0.081^{\star \star}$ \\
\hline
\end{tabular}

Predictors were included if they explained at least additional $2 \%$ of variance.

${ }^{*} p<0.05$.

${ }^{* *} p<0.01$.

${ }^{* * *} p<0.001$.

of the COPSOQ and the short version of the ERI-questionnaire. Conducted in the scope of psychosocial risk assessment, we wanted to give a first insight into possible psychosocial stressors and associated strain outcomes in this rarely researched industrial sector and to assess the usefulness of both measures for hazard analysis in a heterogenous workforce. As principal results, the ANOVA showed that belonging to the white- or blue-collar working group explained greater variations in the COPOSQ's scales than in the scales of ERI. Since measures of hazard analysis must reliably distinguish stressors between occupational groups, the wide-ranged measurement approach of the COPSOQ appears suitable for this purpose. Considering the stress-strain relation, hierarchical multiple regression analysis revealed that both the COPSOQ and the ERI explained distinct proportions of variance 
TABLE 8 | Hierarchical regression analysis of predictors of cognitive stress symptoms (Copenhagen Psychosocial Questionnaire model).

\begin{tabular}{|c|c|c|c|}
\hline \multirow[t]{2}{*}{ Predictors } & \multirow{2}{*}{$\frac{\text { Model 1 }}{\beta}$} & \multirow{2}{*}{$\frac{\text { Model } 2}{\beta}$} & \multirow{2}{*}{$\frac{\text { Model } 3}{\beta}$} \\
\hline & & & \\
\hline Working area & 0.029 & 0.054 & 0.010 \\
\hline Gender & 0.233 & 0.219 & 0.193 \\
\hline Age & -0.177 & -0.194 & -0.239 \\
\hline Position & -0.044 & -0.067 & -0.043 \\
\hline Working volume & 0.145 & 0.163 & 0.135 \\
\hline Company affiliation & 0.046 & 0.093 & 0.139 \\
\hline Working experience & 0.061 & -0.032 & -0.044 \\
\hline Type of working contract & -0.017 & -0.042 & 0.006 \\
\hline Work-privacy conflict & & $0.306^{\star \star}$ & $0.284^{\star \star}$ \\
\hline Sense of community & & & 0.170 \\
\hline$R^{2}$ & 0.139 & $0.224^{\star \star}$ & $0.248^{\star \star}$ \\
\hline adj. $R^{2}$ & 0.065 & $0.149^{\star \star}$ & $0.166^{\star \star}$ \\
\hline$\Delta R^{2}$ & 0.139 & $0.085^{\star \star}$ & 0.024 \\
\hline
\end{tabular}

Predictors were included if they explained at least additional $2 \%$ of variance.

${ }^{*} p<0.05$.

${ }^{* *} p<0.01$.

${ }^{* * *} p<0.001$.

TABLE 9 | Hierarchical regression analysis of predictors of satisfaction with life (Copenhagen Psychosocial Questionnaire model).

\begin{tabular}{lcc}
\hline Predictors & Model 1 & Model 2 \\
\cline { 2 - 3 } & \multicolumn{1}{c}{$\boldsymbol{\beta}$} & $\boldsymbol{\beta}$ \\
\hline Working area & $0.206^{\star}$ & 0.124 \\
Gender & -0.026 & -0.034 \\
Age & 0.180 & 0.163 \\
Position & $-0.236^{\star}$ & -0.094 \\
Working volume & $0.478^{\star \star \star}$ & $0.335^{\star \star}$ \\
Company affiliation & -0.143 & -0.136 \\
Working experience & 0.068 & 0.073 \\
Type of working contract & -0.029 & 0.022 \\
Possibilities for development & & $0.391^{\star \star \star}$ \\
$R^{2}$ & $0.297^{\star \star \star}$ & $0.405^{\star \star \star}$ \\
adj. $R^{2}$ & $0.237^{\star \star \star}$ & $0.346^{\star \star \star}$ \\
$\Delta R^{2}$ & $0.297^{\star \star \star}$ & $0.108^{\star \star \star}$
\end{tabular}

Predictors were included if they explained at least additional $2 \%$ of variance.

${ }^{*} p<0.05$.

${ }^{* *} p<0.01$

${ }^{* * *} p<0.001$.

above the covariates. However, the explanatory power of the COPSOQ was significantly stronger with respect to all outcome variables measured. The results of our analysis are discussed below, especially considering conclusions for occupational risk assessment and a comparison between the two questionnaires if appropriate.

We determined a satisfactory discrimination between blueand white-collar workers in the COPSOQ's scales influence at work and degree of freedom at work and significant medium effects with respect to the ERI-ratio and the reward scale. The COPSOQ scales better distinguished between working groups than the ERI-questionnaire, most likely due to its broader measurement approach. Medium to large effects were observed with respect to influence at work and degree of freedom, indicating reasonable and plausible differences between the
TABLE 10 | Hierarchical regression analysis of predictors of job satisfaction (effort-reward imbalance model).

\begin{tabular}{|c|c|c|}
\hline \multirow[t]{2}{*}{ Predictors } & \multirow{2}{*}{$\begin{array}{c}\text { Model } 1 \\
\boldsymbol{\beta}\end{array}$} & \multirow{2}{*}{$\frac{\text { Model } 2}{\beta}$} \\
\hline & & \\
\hline Working area & $0.282^{\star}$ & 0.094 \\
\hline Gender & 0.106 & 0.114 \\
\hline Age & -0.164 & -0.229 \\
\hline Position & $-0.261^{*}$ & -0.107 \\
\hline Working volume & $0.287^{\star}$ & 0.100 \\
\hline Company affiliation & 0.058 & 0.068 \\
\hline Working experience & 0.091 & 0.124 \\
\hline Type of working contract & $-0.240^{\star}$ & $-0.223^{*}$ \\
\hline Reward & & $-0.566^{\star \star \star}$ \\
\hline$R^{2}$ & $0.259^{\star *}$ & $0.49^{\star \star \star}$ \\
\hline adj. $R^{2}$ & $0.187^{\star \star}$ & $0.433^{\star \star \star}$ \\
\hline$\Delta R^{2}$ & $0.259^{\star \star}$ & $0.231^{\star \star \star}$ \\
\hline
\end{tabular}

Predictors were included if they explained at least additional $2 \%$ of variance. ${ }^{*} p<0.05$.

${ }^{* *} p<0.01$.

${ }^{* * *} p<0.001$

TABLE 11 | Hierarchical regression analysis of predictors of personal burnout (effort-reward imbalance model).

\begin{tabular}{|c|c|c|c|}
\hline \multirow[t]{2}{*}{ Predictors } & Model 1 & Model 2 & Model 3 \\
\hline & $\beta$ & $\boldsymbol{\beta}$ & $\beta$ \\
\hline Working area & $0.350^{\star \star}$ & $0.261^{*}$ & $0.238^{\star}$ \\
\hline Gender & 0.161 & 0.156 & 0.148 \\
\hline Age & -0.168 & -0.064 & -0.125 \\
\hline Position & 0.093 & -0.003 & -0.024 \\
\hline Working volume & 0.090 & 0.045 & 0.010 \\
\hline Company affiliation & -0.120 & -0.083 & -0.019 \\
\hline Working experience & 0.131 & 0.075 & 0.074 \\
\hline Type of working contract & 0.059 & 0.159 & 0.155 \\
\hline Effort & & $0.322^{\star \star}$ & $0.231^{\star \star}$ \\
\hline Overcommitment & & & $0.271^{* *}$ \\
\hline$R^{2}$ & $0.186^{\star}$ & $0.271^{\star \star}$ & $0.332^{\star \star \star}$ \\
\hline $\operatorname{adj} . R^{2}$ & $0.112^{*}$ & $0.195^{\star \star}$ & $0.255^{\star \star \star}$ \\
\hline$\Delta R^{2}$ & $0.186^{\star}$ & $0.084^{\star \star}$ & $0.062^{\star \star}$ \\
\hline
\end{tabular}

Predictors were included if they explained at least additional $2 \%$ of variance.

${ }^{*} p<0.05$.

${ }^{* *} p<0.01$.

${ }^{* * *} p<0.001$.

blue- and the white-collar group. Expected differences in workprivacy conflict could not be detected. In general, work-life conflicts are usually investigated in white-collar occupations whereas it is of equal importance in blue-collar occupations (65). However, some factors assessed by the COPSOQ (e.g., meaning of work, quality of leadership, commitment) are of a general scope and may hardly provide information about specific groups. Concerning the ERI scales, both the reward scale and the ratio distinguished between working groups with medium effect sizes. As the reward scale also assesses aspects of satisfaction ("Considering all my efforts and achievements, my salary/income is adequate"), this scale differs considerably from others, such as degree of freedom at work, which rather characterizes the work activity as such. Congruent reflections may apply in view of the ratio as a type of a general self-rated 
TABLE 12 | Hierarchical regression analysis of predictors of cognitive stress symptoms (effort-reward imbalance model).

\begin{tabular}{|c|c|c|c|}
\hline \multirow[t]{2}{*}{ Predictors } & \multirow{2}{*}{$\frac{\text { Model 1 }}{\beta}$} & \multirow{2}{*}{$\frac{\text { Model } 2}{\beta}$} & \multirow{2}{*}{$\frac{\text { Model } 3}{\beta}$} \\
\hline & & & \\
\hline Working area & 0.038 & -0.025 & -0.050 \\
\hline Gender & 0.188 & 0.185 & 0.176 \\
\hline Age & -0.159 & -0.086 & -0.155 \\
\hline Position & -0.022 & -0.089 & -0.113 \\
\hline Working volume & 0.185 & 0.154 & 0.114 \\
\hline Company affiliation & 0.006 & 0.031 & 0.104 \\
\hline Working experience & 0.029 & -0.011 & -0.012 \\
\hline Type of working contract & -0.022 & 0.048 & 0.044 \\
\hline Effort & & 0.226 & 0.124 \\
\hline Overcommitment & & & 0.306 \\
\hline$R^{2}$ & 0.138 & $0.180^{*}$ & $0.258^{\star *}$ \\
\hline adj. $R^{2}$ & 0.060 & $0.095^{\star}$ & $0.172^{\star \star}$ \\
\hline$\Delta R^{2}$ & 0.138 & $0.042^{\star}$ & $0.079^{\star \star}$ \\
\hline
\end{tabular}

Predictors were included if they explained at least additional $2 \%$ of variance.

${ }^{*} p<0.05$.

${ }^{* *} p<0.01$

${ }^{* * *} p<0.001$

TABLE 13 | Hierarchical regression analysis of predictors of life satisfaction (effort-reward imbalance model).

\begin{tabular}{|c|c|c|}
\hline \multirow[t]{2}{*}{ Predictors } & \multirow{2}{*}{$\frac{\text { Model 1 }}{\beta}$} & \multirow{2}{*}{$\frac{\text { Model } 2}{\beta}$} \\
\hline & & \\
\hline Working area & $0.210^{\star}$ & 0.108 \\
\hline Gender & -0.076 & -0.072 \\
\hline Age & 0.137 & 0.100 \\
\hline Position & $-0.217^{\star}$ & -0.133 \\
\hline Working volume & $0.562^{\star \star \star}$ & $0.460^{\star \star}$ \\
\hline Company affiliation & -0.138 & -0.132 \\
\hline Working experience & 0.063 & 0.084 \\
\hline Type of working contract & -0.063 & -0.054 \\
\hline Reward & & $-0.310^{\star \star}$ \\
\hline$R^{2}$ & $0.326^{\star \star \star}$ & $0.395^{\star \star \star}$ \\
\hline adj. $R^{2}$ & $0.260^{\star \star \star}$ & $0.328^{\star \star \star}$ \\
\hline$\Delta R^{2}$ & $0.326^{\star \star \star}$ & $0.069^{\star \star}$ \\
\hline
\end{tabular}

Predictors were included if they explained at least additional $2 \%$ of variance.

${ }^{*} p<0.05$.

${ }^{* *} p<0.01$.

${ }^{* * *} p<0.001$

evaluation parameter of work in contrary to a descriptive rating of work characteristics. Thus, since reference values are not available for the ERI-questionnaire and as the characteristics that underlie the reward scale and the ratio are of a more general nature, inferences regarding hazard analysis must be drawn with caution. We finally conclude that both instruments can reliably distinguish distinct types of psychosocial work stress in different occupational groups, albeit the variety of the COPSOQ scales allows a much broader and more precise analysis, indicating its worth for hazard analysis.

With respect to associations between stressors and strain outcomes, hierarchical multiple regression analysis revealed that the COPSOQ had a stronger explanatory power than the ERI-questionnaire, with respect to all measured outcomes. In both models, job satisfaction was the outcome best explained by psychosocial work stressors. This is interesting, as job satisfaction is not only the outcome related most closely to the self-rated work situation (43) but also a potential indicator for further factors such as organizational citizenship behavior $(66,67)$ and job performance (68). Furthermore, the COPSOQ model explained substantial proportions of variance in all outcomes, also in intention to leave the job and general health, compared to the ERI model. However, one has to consider that the COPSOQ encompasses more scales, which we assume to be the reason for its higher discriminant and predictive ability in our study. Even though the ERI-ratio was shown to be a potent predictor with respect to health behavior (69), endocrine, and immunological stress reactions $(31,70)$ and especially cardiovascular morbidity and mortality $(71,72)$, we could not predict strain outcomes using the ERI-ratio in the present sample. In contrast, the predictive power of the German COPSOQ regarding diagnosed clinical diseases and disorders is scarcely researched to date. A single ratio as provided by the ERI might be an easier and more precise measure for this purpose. However, it is not surprising that a shortened questionnaire, especially designed for large scale epidemiological studies, may not attain the same but nevertheless an adequate power in predicting the outcome of interest. Furthermore, our findings indicated the combination of both questionnaires not to be fruitful, as we could not determine any helpful contribution.

Looking at the results of the hierarchical regression analysis, it becomes apparent that, even when covariates had a high explanatory power, like age in general health $(\beta=0.408)$ or working volume in life satisfaction $(\beta=0.335)$, a reasonable impact of psychosocial working conditions on organizational and health-related outcomes can be observed in all models, strengthening the legitimacy and relevance of assessing psychosocial hazards in this industrial sector. Notably, work-privacy conflict was an important predictor of various strain indices. Issues of work-life balance are known to be of particular importance for health and well being (73-75). Even though efforts to implement measures that facilitate flexible work schedules have increased in the past years, conducting risk mitigation and workplace health promotion to comprehensively tackle work-privacy aspects, will surely result in enormous challenges for OHS as well as organizations, particularly with respect to blue-collar occupations organized in shift systems. Appropriate solutions might even demand new forms of work systems design. In this respect, we assume the most problematic aspects not to arise from designing measures for risk mitigation. As Nordlöf et al. (76) have demonstrated in a sample of the Swedish steel industry, a trade-off between productivity and safety in favor of the first seems to impede working safely. This was mainly determined by practical obstacles such as inappropriate or broke equipment, and the management's expectations that production levels should be maintained constant even if staffing was low. Kiani and Khodabakhsh (77) found evidence for an association between employees' perception of management safety practices and the tendency to report injuries in the Iranian steel industry. Finally, a poor access to mitigation resources has been shown to relate to the risk of workplace injury (78). This depicts the usual predominant role of the economic and technical element in such 
socio-technical systems. Keeping in mind that operational OHS, at least in Germany, has a consultative instead of an executive role, planning, designing, and implementing measures for risk mitigation might only play a minor role when confronted with daily business. We argue that psychosocial hazards have "hidden costs" which do not directly appear in organizations' performance indicators, like for instance in sickness presentism. On the one hand, this is of course a matter of what is being measured in controlling departments. On the other hand, however, the interpretation of a latent psychosocial hazard-and this might apply for the construct of work stress in general-with a latent cost effect might seem more difficult for organizations than apparent and well-known business performance indicators. One can also speculate that data on health constraints, such as mental health, are mostly sourced from data of health insurance companies, and thus interpreted as being "something from the outside." A possible solution in this respect might be to focus more on intervention studies. Improvements resulting from such measures can indicate the significance of psychosocial hazards in a sense of reversed causality. Conducting further research to clarify the hazardous character of psychosocial factors at work and their economic impact, and transferring this knowledge into standards, legal recommendations, and guidelines might be a practicable solution to support OHS in its ability to act.

\section{Strengths and Limitations of the Study}

We are not aware of any other studies that quantitatively evaluated the role of psychosocial workload and related outcomes by validated instruments in the European steel industry. A straightforward comparison between COPSOQ and ERI appears to be difficult because of the different structural and theoretical assumptions of both instruments. As the present study is based on cross-sectional data, causality cannot be inferred. However, the theoretical framework proposes psychosocial workload to be the predictor and strain the criterion. Particularly in terms of occupational risk assessment, the hazardous character of psychosocial work-related stress is conceptualized as the mediator between risk exposure and health outcomes (79). A related issue in cross-sectional studies is the possibility of reverse and reciprocal causation (64). Referring to our analysis and to scientific literature, we claim that psychosocial factors at work have a plausible impact on associated outcomes. Yet, it has to be considered that for instance being highly content with work can likewise affect the perception of working conditions (80). Finally, the assessment of workload and strain via identical measures can result in common-method bias. However, by emphasizing the practical focus of this study, we assume a significant predictor to be relevant even if its variance might be inflated.

The final question that arises is how the present analyses generate new insights into occupational stress research and practice. We would like to stress that the broad and universal approach used in this study is only partially comparable with other investigations as such data from the European steel industry is hardly available. In contrast to most other studies, we included both blue- and white-collar workers to approximate the conditions of a heterogeneous workforce. Overall, it becomes apparent that the often so called "soft factors" seem to play an important role in an industrial environment that has mostly been researched in view of workers being exposed to "hard factors" in the past. Especially stressors relating to socioemotional aspects seem to have a reasonable impact. One can, therefore, conclude that the still more technically and medically oriented field of OHS should pay more attention to such factors. Notably, not all scales emerging as important predictors in the regression analyses revealed themselves as obvious risk factors in the comparison of average ratings with the reference values. There seems to be a need for statistical analysis in psychosocial risk assessment, which should be discussed further. Including confounders at the individual level, however, might compromise data protection. This implies that operational OHS in this sector will be confronted with new challenges, also in terms of risk mitigation and elimination, as interventions for mastering these risk factors might require comprehensive solutions at the organizational level. We are of course aware that the generalizability of the present results is limited, drawing conclusion with respect to a whole industry is, therefore, impossible. Rather than doing so, we want to provide a first insight into a multifaceted and economically important industrial sector, stressing the need for further investigations in this respect. Since especially psychosocial risk assessment proves to be a major challenge to organizations, we want to offer a perspective both for scientists and practitioners on how psychosocial hazards can be assessed in a complex working environment.

\section{CONCLUSION}

Against the backdrop of psychosocial risk assessment, this study was conducted to gain insight into psychosocial stress and strain of employees working in the European steel industry. Considering the heterogeneous workforce of the steel industry, the German standard version of the COPSOQ- and the short version of the ERI-questionnaire were used to provide a broad measurement approach. Results revealed stronger effects sizes of partial eta ${ }^{2}$ within the COPSOQ scales in discriminating white- and blue-collar workers. Adjusted for covariates, the COPSOQ also showed a higher power in predicting outcomes like the intention to quit the job, job satisfaction, or personal burnout, presumably due to its greater variety of scales contrary to the ERI. The combination of both instruments did not result in any remarkable gain in explained variance. As the investigations revealed variables such as work-privacy conflict, meaning of work, and social support to be important predictors of the strain indices, our findings underline the significant role of especially socioemotional factors at work also in the European steel industry, indicating new fields of actions and challenges for OHS.

\section{ETHICS STATEMENT}

This study was carried out in accordance with the recommendations and approved by the occupational review boards for data protection and work safety. No written informed consent was 
obtained; instead the common company specific procedures were applied: A working councils agreement including the data protection officers agreement ensuring compliance with all relevant privacy policy regulations according to German law was adopted. A member of the working council was present during the data collection process to ensure compliance with the agreement and to guarantee anonymity and voluntary participation.

\section{REFERENCES}

1. Agostini M, Bauchiere D, Beaufort P, Montreuil E, van Criekingen L, Weingarten J. Industrial Relations Practices Related to Psychosocial Constraints at Work in the Steel Sector. Dublin: Eurofound; grey literature (2014).

2. Eurofound. Metal Industry: Working Conditions and Job Quality. Dublin: Eurofound; grey literature (2014). Available from: https://www.eurofound. europa.eu/sites/default/files/ef_publication/field_ef_document/ef1384en7. pdf

3. Vinck L. Les risques professionnels par secteur d'activité: Enquête Sumer 2010. Direction de lanimation de la recherche, des études et des statistiques (DARES) (2014).

4. Lohman-Haislah A. Stressreport Deutschland 2012: Psychische Anforderungen, Ressourcen und Befinden. Dortmund: Bundesanstalt für Arbeitsschutz und Arbeitsmedizin (2012).

5. Karasek RA. Job demands, job decision latitude, and mental strain: implications for job redesign. Adm Sci Q (1979) 24(2):285. doi:10.2307/2392498

6. Siegrist J. Adverse health effects of high-effort/low-reward conditions. J Occup Health Psychol (1996) 1(1):27-41. doi:10.1037/1076-8998.1.1.27

7. Stansfeld S, Candy B. Psychosocial work environment and mental health a meta-analytic review. Scand J Work Environ Health (2006) 32(6):443-62. doi:10.5271/sjweh. 1050

8. Siegrist J, Dragano N. Psychosoziale Belastungen und Erkrankungsrisiken im Erwerbsleben: befunde aus internationalen Studien zum AnforderungsKontroll-Modell und zum Modell beruflicher Gratifikationskrisen. Bundesgesundheitsblatt Gesundheitsforschung Gesundheitsschutz (2008) 51(3):305-12. doi:10.1007/s00103-008-0461-5

9. Backé E-M, Seidler A, Latza U, Rossnagel K, Schumann B. The role of psychosocial stress at work for the development of cardiovascular diseases: a systematic review. Int Arch Occup Environ Health (2012) 85(1):67-79. doi:10.1007/s00420-011-0643-6

10. Beguin J-M, Carley M. Industrial Relations in the Steel Industry. Dublin: Eurofound; grey literature (2005).

11. Kieselbach T, Armgarth E, Bagnara S, Elo A-L, Jefferys S, Joling C, et al. Health in Restructuring: Innovative Approaches and Policy Recommendations. Mering: Rainer Hampp Verlag (2009).

12. International Iron and Steel Institute, United Nations Environment Programme. Steel Industry and the Environment: Technical and Management Issues. Brussels, Paris: United Nations Environment Programe, Industry \& Environment Office; grey literature (1997).

13. International Labour Organization. Code of Practice on Safety and Health in the Iron and Steel Industry. Geneva: International Labour Office; grey literature (2005).

14. Malchaire JB, Rezk-Kallah B. Evaluation of the physical work load of bricklayers in the steel industry. Scand J Work Environ Health (1991) 17(2):110-6. doi:10.5271/sjweh.1729

15. Hildebrandt VH, Bongers PM, Dul J, van Dijk FJ, Kemper HC. Identification of high-risk groups among maintenance workers in a steel company with respect to musculoskeletal symptoms and workload. Ergonomics (1996) 39(2):232-42. doi:10.1080/00140139608964454

16. Suadicani P, Hansen K, Fenger A-M, Gyntelberg F. Low back pain in steelplant workers. Occup Med (1994) 44(4):217-21. doi:10.1093/occmed/44.4.217

17. Büssing A. Can control at work and social support moderate psychological consequences of job insecurity: results from a quasi-experimental study in the steel industry. Eur J Work Organ Psychol (1999) 8(2):219-42. doi:10.1080/135943299398339

18. Hakola T, Härmä M. Evaluation of a fast forward rotating shift schedule in the steel industry with a special focus on ageing and sleep. J Hum Ergol (2001) 30(1-2):315-9.

\section{AUTHOR CONTRIBUTIONS}

All authors have made substantial contributions, including each of the following: (1) the conception and design of the study, or acquisition of data, or analysis and interpretation of data, (2) drafting the article or revising it critically for important intellectual content, or (3) final approval of the version to be submitted.

19. Viitasalo K, Kuosma E, Laitinen J, Härmä M. Effects of shift rotation and the flexibility of a shift system on daytime alertness and cardiovascular risk factors. Scand J Work Environ Health (2008) 34(3):198-205. doi:10.5271/sjweh.1228

20. Pueyo V, Toupin C, Volkoff S. The role of experience in night work: lessons from two ergonomic studies. Appl Ergon (2011) 42(2):251-5. doi:10.1016/j. apergo.2010.06.015

21. Council of the European Communities. Council Directive of 12 June 1989 on the Introduction of Measures to Encourage Improvements in the Safety and Health of Workers at Work: 89/391/EEC. Official Journal of the European Communities, No L 183/1 (1989).

22. European Commission. Guidance on Risk Assessment at Work: Health and Safety. Brussels, Luxembourg: Office for Official Publications of the European Communities (1996).

23. Tabanelli MC, Depolo M, Cooke RM, Sarchielli G, Bonfiglioli R, Mattioli S, et al. Available instruments for measurement of psychosocial factors in the work environment. Int Arch Occup Environ Health (2008) 82(1):1-12. doi:10.1007/s00420-008-0312-6

24. Leka S, Jain A. Health Impact of Psychosocial Hazards at Work: An Overview. Geneva: WHO Press (2010).

25. Schulz P, Schlotz W. Trierer Inventar zur Erfassung von chronischem Streß (TICS): skalenkonstruktion, teststatistische Überprüfung und Validierung der Skala Arbeitsüberlastung. Diagnostica (1999) 45(1):8-19. doi:10.1026//0012-1924.45.1.8

26. Rimann M, Udris I. Subjektive arbeitsanalyse: der fragebogen SALSA. In: Strohm O, Ulich E, editors. Unternehmen arbeitspsychologisch bewerten: Ein Mehr-Ebenen-Ansatz unter besonderer Berücksichtigung von Mensch, Technik und Organisation. Zurich: vdf (1997). p. 281-98.

27. Semmer NK, Zapf D, Dunckel H. Instrument zur streßbezogenen Tätigkeitsanalyse ISTA. In: Dunckel $\mathrm{H}$, editor. Handbuch Psychologischer Arbeitsanalyseverfahren. Zurich: vdf (1999). p. 179-204.

28. van Vegchel N, de Jonge J, Bosma H, Schaufeli W. Reviewing the effort-reward imbalance model: drawing up the balance of 45 empirical studies. Soc Sci Med (2005) 60(5):1117-31. doi:10.1016/j.socscimed.2004.06.043

29. du Prel J-B, March S, Schröder H, Peter R. Berufliche Gratifikationskrisen und Arbeitsunfähigkeit in Deutschland: querschnittsergebnisse aus der lidA(leben in der Arbeit)-Studie. Bundesgesundheitsblatt Gesundheitsforschung Gesundheitsschutz (2015) 58(9):996-1004. doi:10.1007/s00103-015-2207-5

30. Aboa-Éboulé C, Brisson C, Maunsell E, Bourbonnais R, Vézina M, Milot A, et al. Effort-reward imbalance at work and recurrent coronary heart disease events: a 4-year prospective study of post-myocardial infarction patients. Psychosom Med (2011) 73(6):436-47. doi:10.1097/PSY.0b013e318222b2d8

31. Bellingrath S, Rohleder N, Kudielka BM. Healthy working school teachers with high effort-reward-imbalance and overcommitment show increased pro-inflammatory immune activity and a dampened innate immune defence. Brain Behav Immun (2010) 24(8):1332-9. doi:10.1016/j. bbi.2010.06.011

32. Siegrist J. Contributions of sociology to the prediction of heart disease and their implications for public health. Eur J Public Health (1991) 1(1):10-21. doi:10.1093/eurpub/1.1.10

33. Bellingrath S, Kudielka BM. Effort-reward-imbalance and overcommitment are associated with hypothalamus-pituitary-adrenal (HPA) axis responses to acute psychosocial stress in healthy working schoolteachers. Psychoneuroendocrinology (2008) 33(10):1335-43. doi:10.1016/j.psyneuen. 2008.07.008

34. Reimann $\mathrm{M}$. The moderating role of overcommitment in the relationship between psychological contract breach and employee mental health. J Occup Health (2016) 58(5):425-33. doi:10.1539/joh.16-0032-OA

35. Eddy P, Heckenberg R, Wertheim EH, Kent S, Wright BJ. A systematic review and meta-analysis of the effort-reward imbalance model of workplace 
stress with indicators of immune function. J Psychosom Res (2016) 91:1-8. doi:10.1016/j.jpsychores.2016.10.003

36. Schmidt B, Bosch JA, Jarczok MN, Herr RM, Loerbroks A, van Vianen AE, et al. Effort-reward imbalance is associated with the metabolic syndrome findings from the Mannheim Industrial Cohort Study (MICS). Int J Cardiol (2015) 178:24-8. doi:10.1016/j.ijcard.2014.10.115

37. Li J, Jarczok MN, Loerbroks A, Schöllgen I, Siegrist J, Bosch JA, et al. Work stress is associated with diabetes and prediabetes: cross-sectional results from the MIPH industrial cohort studies. Int J Behav Med (2013) 20(4):495-503. doi:10.1007/s12529-012-9255-0

38. Kristensen TS, Borg V. AMI’s spørgeskema om psykisk arbejdsmiljø. Copenhagen: National Institute of Occupational Health (2000).

39. Kristensen TS, Hannerz H, Høgh A, Borg V. The Copenhagen psychosocial questionnaire - a tool for the assessment and improvement of the psychosocial work environment. Scand J Work Environ Health (2005) 31(6):438-49. doi:10.5271/sjweh.948

40. Kompier MA. Job design and well-being. In: Schabracq MJ, Winnubst JA, Cooper CL, editors. The Handbook of Work and Health Psychology. Chichester, UK: John Wiley \& Sons Ltd (2003). p. 429-54.

41. Setterlind S, Larsson G. The stress profile: a psychosocial approach to measuring stress. Stress Med (1995) 11(1):85-92. doi:10.1002/smi.2460110116

42. Ware JE, Sherbourne CD. The MOS 36-item short-form health survey (SF-36): I. Conceptual framework and item selection. Med Care (1992) 30(6):473-83. doi:10.1097/00005650-199206000-00002

43. Nübling M, Seidler A, Garthus-Niegel S, Latza U, Wagner M, Hegewald J, et al. The Gutenberg Health Study: measuring psychosocial factors at work and predicting health and work-related outcomes with the ERI and the COPSOQ questionnaire. BMC Public Health (2013) 13:538. doi:10.1186/1471-2458-13-538

44. Nübling M, Stößel U, Hasselhorn H-M, Michaelis M, Hofmann F. Methoden zur Erfassung psychischer Belastungen: Erprobung eines Messinstrumentes (COPSOQ). Bremerhaven: Wirtschaftsverlag NW Verlag für neue Wissenschaft $\mathrm{GmbH}(2005)$.

45. Pejtersen JH, Kristensen TS, Borg V, Bjorner JB. The second version of the Copenhagen Psychosocial Questionnaire. Scand J Public Health (2010) 38 (3 Suppl):8-24. doi:10.1177/1403494809349858

46. Lund T, Labriola M, Christensen KB, Bültmann U, Villadsen E, Burr H. Psychosocial work environment exposures as risk factors for long-term sickness absence among Danish employees: results from DWECS/DREAM. J Occup Environ Med (2005) 47(11):1141-7. doi:10.1097/01.jom.0000174301. 80318.f2

47. Rugulies R, Bültmann U, Aust B, Burr H. Psychosocial work environment and incidence of severe depressive symptoms: prospective findings from a 5-year follow-up of the Danish work environment cohort study. Am JEpidemiol (2006) 163(10):877-87. doi:10.1093/aje/kwj119

48. da Costa BR, Vieira ER. Risk factors for work-related musculoskeletal disorders: a systematic review of recent longitudinal studies. Am J Ind Med (2010) 53(3):285-323. doi:10.1002/ajim.20750

49. Côté P, van der Velde G, Cassidy JD, Carroll LJ, Hogg-Johnson S, Holm LW, et al. The burden and determinants of neck pain in workers: results of the bone and joint decade 2000-2010 task force on neck pain and its associated disorders. Spine (2008) 33(4 Suppl):S60-74. doi:10.1097/ BRS.0b013e3181643ee4

50. van Rijn RM, Huisstede BM, Koes BW, Burdorf A. Associations between work-related factors and the carpal tunnel syndrome - a systematic review. Scand J Work Environ Health (2009) 35(1):19-36. doi:10.5271/sjweh.1306

51. Theorell T, Hammarstrom A, Aronsson G, Traskman Bendz L, Grape T, Hogstedt C, et al. A systematic review including meta-analysis of work environment and depressive symptoms. BMC Public Health (2015) 15:738. doi:10.1186/s12889-015-1954-4

52. Harvey SB, Modini M, Joyce S, Milligan-Saville JS, Tan L, Mykletun A, et al. Can work make you mentally ill? A systematic meta-review of work-related risk factors for common mental health problems. Occup Environ Med (2017) 74(4):301-10. doi:10.1136/oemed-2016-104015

53. Cohen-Charash Y, Spector PE. The role of justice in organizations: a meta-analysis. Organ Behav Hum Decis Process (2001) 86(2):278-321. doi:10.1006/obhd.2001.2958
54. Rhoades L, Eisenberger R. Perceived organizational support: a review of the literature. J Appl Psychol (2002) 87(4):698-714. doi:10.1037/0021-9010.87.4.698

55. Kiani F, Samavatyan H, Pourabdian S, Jafari E. Predictive power of incidents reporting rate and its dimensions by job stress among workers' Isfahan steel company. Iran J Public Health (2011) 40(3):105-12.

56. Cooper CL, Liukkonen P, Cartwright S. Stress Prevention in the Workplace: Assessing the Costs and Benefits to Organisations. Dublin: Office for Official Publications of the European Communities (1996).

57. Leineweber $\mathrm{C}$, Wege $\mathrm{N}$, Westerlund $\mathrm{H}$, Theorell $\mathrm{T}$, Wahrendorf $\mathrm{M}$, Siegrist J. How valid is a short measure of effort-reward imbalance at work? A replication study from Sweden. Occup Environ Med (2010) 67(8):526-31. doi:10.1136/oem.2009.050930

58. Freiburger Forschungsstelle für Arbeitswissenschaften. COPSOQ StandardFragebogen. Freiburg (2015). Available from: https://www.copsoq.de/assets/ COPSOQ-Standard-Fragebogen-FFAW.pdf

59. Nübling $M$, Vomstein $M$, Nübling $T$, Stößel $U$, Hasselhorn H-M, Hofmann F. Erfassung psychischer Belastungen anhand eines erprobten Fragebogens - Aufbau der COPSOQ-Datenbank. Bremerhaven: Wirtschaftsverlag NW Verlag für neue Wissenschaft GmbH (2011).

60. Fritz CO, Morris PE, Richler JJ. Effect size estimates: current use, calculations, and interpretation. J Exp Psychol Gen (2012) 141(1):2-18. doi:10.1037/ a0024338

61. Cohen J. Statistical Power Analysis for the Behavioral Sciences. Hillsdale, NJ: Lawrence Erlbaum Associates (1988).

62. Federal Institute for Occupational Safety and Health. Gefährdungsbeurteilung psychischer Belastung: Erfahrungen und Empfehlungen. Berlin: Schmidt (2014).

63. Cortina JM. What is coefficient alpha? An examination of theory and applications. J Appl Psychol (1993) 78(1):98-104. doi:10.1037/0021-9010.78.1.98

64. Zapf D, Dormann C, Frese M. Longitudinal studies in organizational stress research: a review of the literature with reference to methodological issues. J Occup Health Psychol (1996) 1(2):145-69. doi:10.1037/1076-8998.1.2.145

65. Hämmig O. Prevalence and health correlates of work-life conflict among blue- and white-collar workers from different economic sectors. Front Public Health (2014) 2:221. doi:10.3389/fpubh.2014.00221

66. Organ DW, Ryan K. A meta-analytic review of attitudinal and dispositional predictors of organizational citizenship behaviour. Pers Psychol (1995) 48(4):775-802. doi:10.1111/j.1744-6570.1995.tb01781.x

67. LePine JA, Erez A, Johnson DE. The nature and dimensionality of organizational citizenship behavior: a critical review and meta-analysis. J Appl Psychol (2002) 87(1):52-65. doi:10.1037/0021-9010.87.1.52

68. Judge TA, Thoresen CJ, Bono JE, Patton GK. The job satisfaction-job performance relationship: a qualitative and quantitative review. Psychol Bull (2001) 127(3):376-407. doi:10.1037/0033-2909.127.3.376

69. Siegrist J, Rödel A. Work stress and health risk behavior. Scand J Work Environ Health (2006) 32(6):473-81. doi:10.5271/sjweh.1052

70. Bellingrath S, Weigl T, Kudielka BM. Chronic work stress and exhaustion is associated with higher allostastic load in female school teachers. Stress (2009) 12(1):37-48. doi:10.1080/10253890802042041

71. Kivimäki M, Leino-Arjas P, Luukkonen R, Riihimaki H, Vahtera J, Kirjonen J. Work stress and risk of cardiovascular mortality: prospective cohort study of industrial employees. BMJ (2002) 325(7369):857. doi:10.1136/ bmj.325.7369.857

72. Kuper H, Singh-Manoux A, Siegrist J, Marmot M. When reciprocity fails: effort-reward imbalance in relation to coronary heart disease and health functioning within the Whitehall II study. Occup Environ Med (2002) 59(11):777-84. doi:10.1136/oem.59.11.777

73. Garthus-Niegel S, Hegewald J, Seidler A, Nubling M, Espinola-Klein C, Liebers F, et al. The Gutenberg health study: associations between occupational and private stress factors and work-privacy conflict. BMC Public Health (2016) 16:192. doi:10.1186/s12889-016-2881-8

74. Hämmig O, Gutzwiller F, Bauer G. Work-life conflict and associations with work- and nonwork-related factors and with physical and mental health outcomes: a nationally representative cross-sectional study in Switzerland. BMC Public Health (2009) 9:435. doi:10.1186/1471-2458-9-435

75. Fransson EI, Heikkila K, Nyberg ST, Zins M, Westerlund H, Westerholm P, et al. Job strain as a risk factor for leisure-time physical inactivity: an 
individual-participant meta-analysis of up to 170,000 men and women: the IPD-Work Consortium. Am J Epidemiol (2012) 176(12):1078-89. doi:10.1093/ aje/kws336

76. Nordlöf H, Wiitavaara B, Winblad U, Wijk K, Westerling R. Safety culture and reasons for risk-taking at a large steel-manufacturing company: investigating the worker perspective. Saf Sci (2015) 73:126-35. doi:10.1016/j. ssci.2014.11.020

77. Kiani F, Khodabakhsh MR. Preventing injuries in workers: the role of management practices in decreasing injuries reporting. Int J Health Policy Manag (2014) 3(4):171-7. doi:10.15171/ijhpm.2014.83

78. Lay AM, Saunders R, Lifshen M, Breslin C, LaMontagne A, Tompa E, et al. Individual, occupational, and workplace correlates of occupational health and safety vulnerability in a sample of Canadian workers. Am J Ind Med (2016) 59(2):119-28. doi:10.1002/ajim.22535

79. Cox T, Griffths A, Randall R. A risk management approach to the prevention of work stress. In: Schabracq MJ, Winnubst JA, Cooper CL, editors. The Handbook of Work and Health Psychology. Chichester, UK: John Wiley \& Sons Ltd (2003). p. 191-206.
80. de Lange AH, Taris TW, Kompier MA, Houtman IL, Bongers PM. The relationships between work characteristics and mental health: examining normal, reversed and reciprocal relationships in a 4-wave study. Work Stress (2004) 18(2):149-66. doi:10.1080/02678370412331270860

Conflict of Interest Statement: The lead author discloses that he is partly employed in the company in which the study took place within his doctoral thesis. The authors wish to confirm that there are no further known conflicts of interest associated with this publication and there has been no significant financial support for this work that could have influenced its outcome.

Copyright $\odot 2017$ Metzler and Bellingrath. This is an open-access article distributed under the terms of the Creative Commons Attribution License (CC BY). The use, distribution or reproduction in other forums is permitted, provided the original author(s) or licensor are credited and that the original publication in this journal is cited, in accordance with accepted academic practice. No use, distribution or reproduction is permitted which does not comply with these terms. 